\title{
Coordinating Climate and Trade Policies: Pareto Efficiency and the Role of Border Tax Adjustments
}

Michael Keen and Christos Kotsogiannis 
IMF Working Paper

Fiscal Affairs Department

\title{
Coordinating Climate and Trade Policies: Pareto Efficiency and the Role of Border Tax Adjustments
}

\author{
Prepared by Michael Keen and Christos Kotsogiannis*
}

Authorized for distribution by Michael Keen

December 2012

\section{This Working Paper should not be reported as representing the views of the IMF.} The views expressed in this Working Paper are those of the author(s) and do not necessarily represent those of the IMF or IMF policy. Working Papers describe research in progress by the author(s) and are published to elicit comments and to further debate.

\begin{abstract}
This paper explores the role of trade instruments in globally efficient climate policies, focusing on the central issue of whether some form of border tax adjustment (BTA) is warranted when carbon prices differ internationally. It shows that tariff policy has a role in easing cross-country distributional concerns that can make non-uniform carbon pricing efficient and, more particularly, that Pareto-efficiency requires a form of BTA when carbon taxes in some countries are constrained, a special case being identified in which this has the simple structure envisaged in practical policy discusions. It also stresses - a point that has been overlooked in the policy debate - that the efficiency case for BTA depends critically on whether climate policies are pursued by carbon taxation or by cap-and-trade.
\end{abstract}

JEL Classification Numbers: H20, F18

Keywords: Environmental taxation, cap-and-trade, international trade, Pareto efficiency, border tax adjustments

Authors’ E-Mail Addresses: mkeen@imf.org, c.kotsogiannis@exeter.ac.uk

\footnotetext{
* Department of Economics, University of Exeter Business School, England, United Kingdom and CESIfo, Munich, Germany. Much of this work was completed while Kotsogiannis was a Visiting Scholar in the Fiscal Affairs Department of the IMF. The authors wish to thank two anonymous referees and the Editor, Brian Copeland; James Markusen; Donald MacLaren; JeanFrancois Tremblay; John Whalley; Alan Woodland; seminar participants at the Universities of Bern, Cyprus, Drexel, Exeter, Heidelberg, Melbourne, Munich, New South Wales; Cardiff Business School; Athens University of Economics and Business; the IMF; the 2010 Canadian Public Economics Group (CPEG) Meeting; the 2011 CESIfo Area Conference on Global Economy; and the University of Exeter 2011 Environmental Protection and Sustainability Forum for helpful comments and suggestions. Kotsogiannis acknowledges support from the Leverhulme Trust. Any remaining erros are the reponsibility of the authors alone.
} 


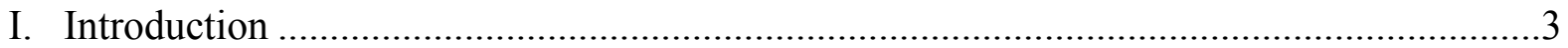

II. Modeling Climate and Trade Policies .........................................................................5

III. The Benchmark: Unconstrained Carbon Tax and Tariff Policies.................................... 8

IV. Pareto Efficiency and the Role of Border Tax Adjustments .......................................10

A. Border Tax Adjustments in the Absence of Distributional Concerns.....................11

B. Border Tax Adjustments in the General Case .................................................15

V. Further Discussion .............................................................................................. 16

A. Comparison with Non-cooperative Policies ......................................................16

B. Border Tax Adjustment and Cap-and-Trade .................................................... 17

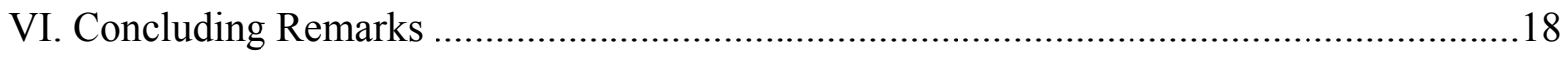

Appendices

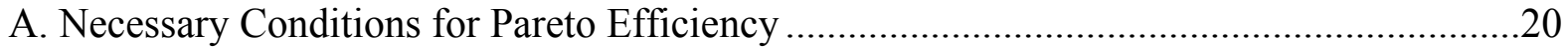

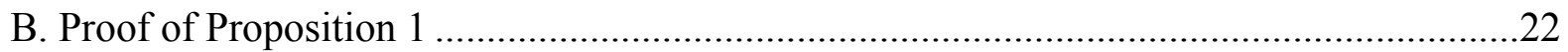

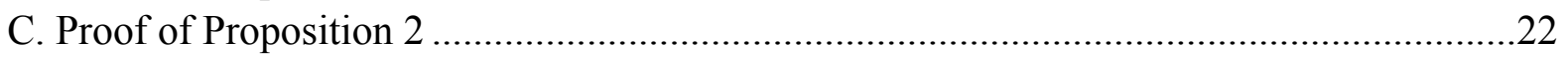

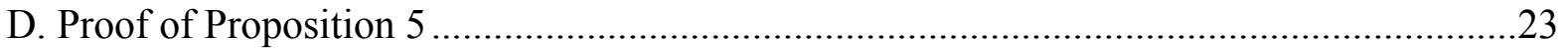

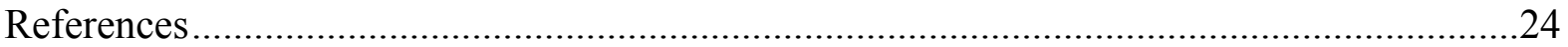




\section{INTRODUCTION}

A key concern in countries contemplating reasonably aggressive carbon pricing-and one that has become still more prominent since the crisis, as they struggle to restore employment-is the fear that their competitive position in world markets would be jeopardized by 'carbon leakage' as production shifts elsewhere. ${ }^{1}$ The likelihood that any mitigation measures will be strongly asymmetric, at least for coming years, amplifies this concern, which is reflected in the inclusion in climate change legislation in both the $\mathrm{EU}^{2}$ and in proposals elsewhere (such as the Waxman-Markey climate and energy bill in the U.S.) of provisions, for exposed emissions-intensive sectors, for various forms of 'border tax adjustment' (BTA) ${ }^{3}$ - meaning the levying of some charge on imports, and remission of charge on exports, to the extent that carbon prices are higher domestically than elsewhere. Unsurprisingly, the appropriateness or not of such adjustments has been the focus of heated debate.

The theoretical literature has begun to address the linkages between climate (environment, more generally) and trade policies that are the heart of this question. Much of it has focused on non-cooperative policy formation, commonly characterizing nationally optimal policy (as in, for instance, Markusen (1975), Baumol and Oates (1988) and Copeland (1996)) or desirable directions of reform - whether for small or large economies - when one or other instrument, environment or trade, is for some reason constrained away from the optimal: see, among others, Copeland (1994), Hoel (1996), Turunen-Red and Woodland (2004) and Neary (2006)).

While this non-cooperative perspective is clearly an important one, an understanding of the requirements of cooperative policy is also valuable. It would certainly be naive to imagine that actual climate policies are entirely shaped to the collective good. But nor are they always easily explained in terms of narrowly defined self-interest. The adoption of carbon pricing in British Columbia, for instance, and the Regional Greenhouse Gas Initiative (capping emissions in several U.S. states) do almost nothing for global emissions, and hence for climate damage, but do impose some local costs. And the EU is undertaking relatively aggressive mitigation policies despite the fact that the costs to its members of adapting to climate change appear quite low (and for some quite possibly negative). ${ }^{4}$ The motives behind these policies are no doubt complex, including perhaps a concern (and some sense of historic guilt) for the harm

\footnotetext{
${ }^{1}$ Instructive discussions of these issues are in Copeland and Taylor (2004) and Sheldon (2006). Levinson and Taylor (2008) provide empirical evidence that more stringent environmental regulation reduces exports.

${ }^{2}$ Adjustments of this kind, in the context of the EU Emission Trading System, are provided for in Directive 2009/29/EC amending Directive 2003/87/EC.

${ }^{3}$ This has also been advocated by, for instance, Stiglitz (2006).

${ }^{4}$ The results in Obsterghaus and Reif (2010), for example, suggest that the fiscal costs of adaptation in the EU would be around 16 billion euros per annum (in 2005 prices) by mid-century, though such figures are subject to considerable uncertainty.
} 
that might be suffered elsewhere and a desire to prod others into action (perhaps all overlain with a fear that delaying action to deal with catastrophic effects could be still more costly). But they certainly seem to reflect more than immediate and narrowly-defined self-interest. Even without delving into motives, in any event, the implications of cooperative design in relation to climate policies must be a central benchmark both given the commonplace rhetoric of cooperation in this area-do policies rationalized from that perspective really make sense? - and, perhaps above all, for assessing the appropriateness of whatever policy structures do emerge. One would at least like to know if policies adopted could be improved in such a way that all countries can benefit.

This collective perspective has, however, received very little attention in the literature (the sole exception of which we are aware being the partial equilibrium treatment in Gros (2009)). The aim in this paper is therefore to explore the interaction between climate and trade policies in a cooperative setting. It does so by characterizing (generally constrained) Pareto-efficient allocations within a standard general equilibrium model of competitive trade in many goods, augmented by a climate-like production externality, in which potentially three sets of policy instruments may be deployed: international lump-sum transfers, carbon pricing, and tariffs. The first of these are naturally directed to equity concerns, moving the world around its utility possibly frontier; the second are naturally targeted to controlling emissions - and the third would have no role if the other two instruments were optimally deployed. Attention thus focuses on the implications of various constraints on these instruments for the setting of the others to achieve constrained Pareto-efficient outcomes. In doing so, the analysis unifies and extends previous results on the links between climate and trade policies.

Within this broad class of issues, attention here focusses especially on the question of whether there are circumstances in which some form of BTA is part of a globally efficient response to climate change (or to any other environmental problem with broadly the same border-crossing structure). By 'border tax adjustment' we shall mean, in the most general interpretation, tariff structures that in some direct way reflect differences in national carbon prices. And of particular interest is the possibility that this adjustment will take the very simple form commonly envisaged in policy discussions-which is likely the only one conceivably practicable — of setting a charge on imports equal to some notion of carbon tax 'not paid' abroad on imports, and remitting tax on exports in similar fashion.

There are of course many other issues raised by the possibility of BTA for carbon prices. These include the questions of whether or not such adjustment is WTO-consistent (see, for instance, Chapter 5 of OECD (2004), and McLure (2011)), ${ }^{5}$ very significant issues of

\footnotetext{
${ }^{5}$ There are precedents, notably in the US Superfund tax and, of particular relevance in the climate context, for ozone-depleting chemicals.
} 
implementability (Moore, 2010); and, not least, the (perhaps limited) empirical significance of the relative producer price effects of carbon pricing that might be adjusted for (Houser et al. 2008). Nor does the analysis here considers the potential merit of BTA as a credible device by which countries implementing carbon pricing can encourage participation by others. ${ }^{6}$ Important though these issues are, they are not the concern here-which is with the pure efficiency case for climate-motivated border tax adjustment.

The plan of the paper is as follows. Section II sets out the model, which takes carbon taxation to be the instrument of climate policy, and Section III then derives benchmark results for collectively efficient carbon tax and tariff policy when both these instruments can be freely set. Section IV considers Pareto-efficient policies when carbon taxes and tariffs are constrained in some countries, showing that there is indeed a case for some form of BTA, both (under weak conditions) in the general sense above and (under strict ones) in the more precise sense of practical policy discussions. Section V then compares these results with those of Markusen (1975) for non-cooperative policy-making, and considers their applicability when carbon pricing is by cap-and-trade rather than carbon taxation. Section VI concludes.

\section{Modeling Climate AND TRADE POLICIES}

The framework is that of Keen and Wildasin (2004), modified to deal with pollution as a by-product of production. We consider a perfectly competitive general equilibrium model of international trade in which there are $J$ countries indexed by the superscript $j$. In each country there is a representative consumer and a private sector that produces (only) $N$ tradeable commodities. The $N$-vector of international commodity prices is denoted by $\mathbf{w} .^{7}$ (All vectors are column vectors, and a prime indicates transposition). Trade is subject to trade taxes or subsidies, denoted by the vector $\tau^{j}$ in country $j$; consistent with most-favored nation rules, each country is assumed to apply the same tariff rates to all others. ${ }^{8}$ The commodity price vector in country $j$ is then given by the $N$-vector $\mathbf{p}^{j}=\mathbf{w}+\boldsymbol{\tau}^{j} .{ }^{9}$

The production of each commodity generates some pollutant—we have in mind carbon

\footnotetext{
${ }^{6}$ Participants themselves presumably gain from the BTAs, and non-participants would then benefit by imposing a carbon price themselves, at least to the extent that since by doing so they would capture revenues otherwise accruing to others (though terms of trade effects would also play a role).

${ }^{7}$ Though world prices are something of a fiction, in the sense that no private agent may trade at them, they do matter for the revenues that national governments collect.

${ }^{8}$ As usual, the model is very general in allowing for all types of trade taxes and subsidies. If $\tau_{i}^{j}>0\left(\tau_{i}^{j}<0\right)$ and commodity $i$ is imported by country $j$, then $\tau_{i}^{j}$ is an import tariff (import subsidy); if $i$ is exported by country $j$ then $\tau_{i}^{j}<0\left(\tau_{i}^{j}>0\right)$ is an export subsidy (export tax).

${ }^{9}$ Consumption taxes are excluded from the analysis as they would be irrelevant for countries that are unconstrained in their use of tariffs and carbon taxes; and would complicate the formalities, with little additional insight, for those that are constrained.
} 
emissions, though there are of course many other possible interpretations ${ }^{10}$ — with the $N$-vector $\mathbf{z}^{j}$ denoting sectoral emissions in country $j$. Total emissions in country $j$ are thus given by $\iota^{\prime} \mathbf{z}^{j}$ where $\iota$ is the $N$-vector of $1 \mathrm{~s}$; and global emissions, on which - as with the concentration of greenhouse gases in the global atmosphere-damage in each country depends, are

$$
k=\sum_{l=1}^{J} \iota^{\prime} \mathbf{z}^{l}
$$

This damage is assumed to arise (only) directly in consumer welfare, not through production; though perhaps not the most realistic assumption in the climate context, this helps relate our results to most familiar analyses and results in the literature. ${ }^{11}$

The representative consumer of country $j$ has preferences represented by the expenditure function

$$
e^{j}\left(u^{j}, \mathbf{p}^{j}, k\right)=\min _{\mathbf{x}^{j}}\left\{\mathbf{p}^{j \prime} \mathbf{x}^{j}: U^{j}\left(\mathbf{x}^{j}, k\right) \geq u^{j}\right\}
$$

with $\mathbf{e}_{\mathbf{p}}^{j}$ the vector of compensated demands and $e_{k}^{j}$, assumed strictly positive in all countries, the compensation required for a marginal increase in global emissions.

Emissions $\mathbf{z}^{j}$ are subject to pollution taxes, given by the $N$-vector $\mathbf{s}^{j}$; these, note, may in general be sector-specific. ${ }^{12}$ Production in country $j$ is competitive and characterized by a revenue function

$$
r^{j}\left(\mathbf{p}^{j}, \mathbf{s}^{j}\right)=\max _{\mathbf{y}^{j}, \mathbf{z}^{j}}\left\{\mathbf{p}^{j \prime} \mathbf{y}^{j}-\mathbf{s}^{j \prime} \mathbf{z}^{j}:\left(\mathbf{y}^{j}, \mathbf{z}^{j}\right) \in T^{j}\right\},
$$

where $T^{j}$ is the technology set and $\mathbf{y}^{j}$ is the (net) output of tradeable goods (the dependence on underlying endowments being omitted for brevity). The revenue function in (3) is convex, linearly homogeneous in $\left(\mathbf{p}^{j}, \mathbf{s}^{j}\right)$ and assumed to be twice continuously differentiable; it is also assumed throughout that all $\mathbf{r}_{\mathrm{ss}}^{j}$ are non-singular. ${ }^{13}$ (The fossil fuels from whose use carbon emissions arise are not explicitly identified, though they can be thought of as being amongst the $N$ commodities, since our interest here is not in their pricing). Hotelling's lemma implies that $\mathbf{r}_{\mathbf{p}}^{j}$ is the vector of net supply functions for tradeable commodities; it also follows from (3) that $\mathbf{r}_{\mathbf{s}}^{j}\left(\mathbf{p}^{j}, \mathbf{s}^{j}\right)=-\mathbf{z}^{j}$ : emissions are given by (minus) the derivative of the revenue function with respect to the sectoral carbon tax rates.

Tax revenues from all sources are assumed to be returned to the domestic consumer in a lump

\footnotetext{
${ }^{10}$ And generalizations too. The analysis and main results are readily generalized to allow for $M$-types of pollutants, and much the same analysis would also apply to pollutants whose emissions do not disperse uniformly in the atmosphere.
${ }^{11}$ Kotsogiannis and Woodland (2012) show that allowing for emissions to instead enter production does not change the essence of the results that follow here.

${ }^{12}$ As in, among others, Copeland (1994), Hoel (1996) and Turunen-Red and Woodland (2004).

${ }^{13}$ For the properties of the revenue function see Dixit and Normal (1980) and Woodland (1982).
} 
sum fashion. At some points, unrequited commodity transfers between countries will be allowed; denoting by the $N$-vector $\boldsymbol{\alpha}^{j}$ that received by $j$, these must satisfy

$$
\sum_{j=1}^{J} \boldsymbol{\alpha}^{j}=\mathbf{0}_{N \times 1}
$$

where $\mathbf{0}_{c}$ denotes the $c$-vector of zeroes. The consumer's budget constraint in country $j$ is thus

$$
e^{j}\left(u^{j}, \mathbf{p}^{j}, k\right)=r^{j}\left(\mathbf{p}^{j}, \mathbf{s}^{j}\right)-\mathbf{s}^{j \prime} \mathbf{r}_{\mathbf{s}}^{j}\left(\mathbf{p}^{j}, \mathbf{s}^{j}\right)+\tau^{j \prime}\left(\mathbf{e}_{\mathbf{p}}^{j}\left(u^{j}, \mathbf{p}^{j}, k\right)-\mathbf{r}_{\mathbf{p}}^{j}\left(\mathbf{p}^{j}, \mathbf{s}^{j}\right)\right)+\mathbf{w}^{\prime} \boldsymbol{\alpha}^{j}
$$

This simply says that expenditure $e^{j}\left(u^{j}, \mathbf{p}^{j}, k\right)$ must equal GDP, given by $r^{j}\left(\mathbf{p}^{j}, \mathbf{s}^{j}\right)$, plus carbon tax revenues $\left(\mathbf{s}^{j \prime} \mathbf{z}^{j}\right)$, tariff revenue $\left(\boldsymbol{\tau}^{j \prime}\left(\mathbf{e}_{\mathbf{p}}^{j}\left(u^{j}, \mathbf{p}^{j}, k\right)-\mathbf{r}_{\mathbf{p}}^{j}\left(\mathbf{p}^{j}, \mathbf{s}^{j}\right)\right)\right)$, and transfers received by country $j\left(\mathbf{w}^{\prime} \boldsymbol{\alpha}^{j}\right)$.

Defining

$$
\mathbf{m}^{j} \equiv \mathbf{e}_{\mathbf{p}}^{j}\left(u^{j}, \mathbf{p}^{j}, k\right)-\mathbf{r}_{\mathbf{p}}^{j}\left(\mathbf{p}^{j}, \mathbf{s}^{j}\right)
$$

the vector of $j$ 's net imports, market clearing requires that

$$
\sum_{j=1}^{J} \mathbf{m}^{j}=\mathbf{0}_{(N-1) \times 1}
$$

where, by Walras' Law, the market-clearing equation for the first commodity is dropped. The same commodity is taken as numeraire, and without loss of generality, to be untaxed in all countries: so $\tau_{1}^{j}=0$ and $p_{1}^{j}=1=w_{1}$, for $j=1, \ldots, J$; it is also assumed throughout that, for all $j, \mathbf{m}_{\mathbf{p}}^{j}$ is non-singular.

Given tariffs $\boldsymbol{\tau}^{j}$ and carbon tax vectors $\mathbf{s}^{j}$, for $j=1, \ldots, J$, a vector of international transfers $\boldsymbol{\alpha}^{j}$ satisfying (4), the market equilibrium conditions (7), and the national budget constraints (5), the system may be solved for the equilibrium world price vector $\mathbf{w}$ and the vector of national utilities $\mathbf{u}=\left(u^{1}, \ldots, u^{J}\right)^{\prime}{ }^{14}$

The analysis that follows uses Motzkin's Theorem of the Alternative to characterize Pareto-efficient carbon tax and tariff structures. The necessary conditions for this are derived in Appendix A. They involve variables $\sigma^{j}$ that can be interpreted as the implicit social marginal value-evaluated at the Pareto-efficient allocation being characterized —of the utility of country $j:{ }^{15}$ if country $i$, say, is more 'income-needy' than country $j$, then $\sigma^{i}>\sigma^{j}$. The discussion and intuition can then proceed as if the problem were one of simply maximizing

\footnotetext{
${ }^{14}$ Differentiability of all functions at the initial equilibrium is assumed. Standard assumptions hold so an equilibrium exists (Woodland (1982)).

${ }^{15}$ This interpretation follows from the formalities in the Appendix A on noting that the conditions in (A.15)-(A.16) are equivalent to those of maximizing a social welfare function $\Omega(\mathbf{u})$ with marginal welfare weights $\Omega_{\mathbf{u}}^{\prime}=\mathbf{y}^{\prime} \boldsymbol{\Lambda}_{\mathbf{u}}$, the typical element of which is $\sigma^{j}\left(e_{u}^{j}-\tau^{j \prime} \mathbf{e}_{\mathbf{p} u}^{j}\right)+\mathbf{v}^{\prime} \mathbf{e}_{\mathbf{p} u}^{j}$. When tariffs and carbon taxes are unconstrained, (B.4) then implies that $\sigma^{j}=\Omega_{u^{j}} / e_{u}^{j}$, so that the $\sigma^{j}$ is the social marginal utility of income of
} 
some social welfare function, having marginal welfare weights $\sigma^{j}$, with the assurance that, behind the scenes, whatever instruments are available can be used to translate what is then expressed as an increase in social welfare into the Pareto improvements that are the ultimate concern here.

\section{The BENChMark: UnCONSTRAINED CARbon TAX AND TARIFF POLICIES}

To fix ideas, this section considers the relatively straightforward case in which there are no constraints on the carbon taxes and tariffs that can be set in any country $j$. Then: ${ }^{16}$

\section{Proposition 1 At any Pareto-efficient allocation:}

(a) The vector of carbon taxes in country $j$ is given by

$$
\sigma^{j} \mathbf{s}^{j}=\left(\sum_{i=1}^{J} \sigma^{i} e_{k}^{i}\right) \boldsymbol{\iota} \mathbf{0}_{N \times 1},
$$

so that for all $j, \mathbf{s}^{j}=\left(\sum_{i=1}^{J} \theta^{i j} e_{k}^{i}\right) \boldsymbol{\iota}$, where $\theta^{i j}=\sigma^{i} / \sigma^{j}$ and $\sigma^{j}>0, j=1, \ldots J$.

(b) The tariff vectors of any pair of countries $j$ and $i$ are collinear:

$$
\boldsymbol{\tau}^{j}=\theta^{i j} \boldsymbol{\tau}^{i}, j, i=1, \ldots, J
$$

Proof: See Appendix B.

The interpretation of part (a) is straightforward, Pareto efficiency requires that each country sets its carbon tax in each sector $n$ to equate the value of the revenue it would lose from a small cut in its own emissions, $\sigma^{j} s_{n}^{j}$, to the sum of the marginal environmental benefits conveyed to all countries, $\sum_{i=1}^{J} \sigma^{i} e_{k}^{i}$. An immediate implication, since the marginal damage from emissions is the same whichever sector they originate in, is that each country should apply the same carbon tax to all activities: within each country, carbon taxes are optimally uniform across sectors. But while each country sets a single carbon tax rate, part (a) also shows that the level of that tax generally differs across countries. Recalling the interpretation of $\sigma^{j}$, Pareto efficiency requires that more 'income-needy' countries impose lower carbon taxes. This is intuitively natural, and to the same effect as the results of Chichilnisky and Heal (1994) and Sandmo $(2005,2006)$ - and consistent too with much of the policy debate, which has emphasized the lesser ability of lower income countries to cope with aggressive carbon pricing. There is though one subtle difference between this and previous results: here the

country $j$; more precisely, $\sigma^{i} / \sigma^{j}$ is the social marginal value of income in country $i$ relative to that in country $j$ for any social welfare function relative to which the allocation is optimal. When instruments are constrained, the interpretation is complicated by the presence of tariffs and demand patterns.

${ }^{16}$ The notation $\mathbf{q} \gg \mathbf{0}$ means that all elements of the vector $\mathbf{q}$ are strictly positive. 
simple equity-based modification of the Pigovian rule applies even though distorting taxes_-tariffs_-may also be deployed.

This brings us to part (b) of Proposition 1, which is more striking. To see why Pareto efficiency requires collinear tariff vectors, consider some change in world prices that increases country $j$ 's import of good $n$ by one unit, and increases $i$ 's exports by one unit. With carbon taxes optimally set, this increases the shadow value of $j$ 's real income by $\sigma^{j} \tau_{n}^{j}$ and reduces that of $i$ by $\sigma^{i} \tau_{n}^{i}$; Pareto efficiency then requires that $\tau_{n}^{j}=\left(\sigma^{i} / \sigma^{j}\right) \tau_{n}^{i}$, and this can hold for all $n$ only if the tariff vectors are collinear. The importance of this is in emphasizing that production inefficiency is generally part of a Pareto efficient allocation. To see this, recall that producer prices in country $j$ are $\mathbf{p}^{j}=\mathbf{w}+\tau^{j}$; this means that global production will be efficient-in the narrow sense that it is impossible to increase global output of any good without reducing the global output of some other-only if the tariff vectors $\tau^{j}$ are the same for all countries. But this is consistent with the collinearity result of Proposition 1(b) only if either $\boldsymbol{\tau}^{j}=\mathbf{0}_{(N-1) \times 1}$ for all countries, or $\theta^{i j}=\sigma^{i} / \sigma^{j}$ takes the same value for all $j$-which there is in general no reason to suppose to be the case.

There is generally production inefficiency in allocations characterized by Proposition 1 in a broader sense too, reflecting also environmental concerns. Maximizing the net output of some good without either reducing the net output of any other or increasing global emissions requires that both producer prices $\mathbf{p}$ and carbon taxes $\mathbf{s}$ be equalized across countries. Proposition 1 points to violations on both of these margins (or neither), driven by distributional concerns: in each case, relative welfare weights shape the proportionality factor between the (sectorally uniform) carbon taxes and tariffs applied by each country.

Proposition 1 applies whether or not international transfers between countries can be deployed. If they can be then, of course, Pareto-efficiency requires equalizing the $\sigma^{j}$ across all countries. Part (a) of Proposition 1 then implies that Pareto efficiency requires the same level of carbon taxes in every country, and part (b) that (with an appropriate normalization) $\boldsymbol{\tau}^{j}=\boldsymbol{\tau}^{i}=\mathbf{0}_{(N-1) \times 1}$. All Pareto-efficient allocations are thus characterized by production efficiency. The same may be true, however, even without international transfers. The reason is as in Keen and Wildasin (2004) and Turunen-Red and Woodland (2004): if there are more goods on which the tariff rates may be varied than there are countries (and sufficient rank in the corresponding matrix of net exports), offsetting tariffs can be designed so as to achieve any desired reallocation of tariff revenue between countries. Explicit transfers are then redundant. Hence:

Proposition 2 If there are no constraints on lump transfers between countries, or there are at least as many goods as countries (and an appropriate rank condition is satisfied), then, at any Pareto-efficient allocation: 
(a) The vector of carbon taxes in every country $j$ is given by

$$
\mathbf{s}^{j}=\mathbf{s}=\left(\sum_{i=1}^{J} e_{k}^{i}\right) \iota \gg \mathbf{0}_{N \times 1}, j=1, \ldots, J
$$

and

(b) tariffs are zero in every country

$$
\boldsymbol{\tau}^{j}=\mathbf{0}_{(N-1) \times 1}, j=1, \ldots, J
$$

Proof: See Appendix C.

Carbon taxes are thus set at first best Pigovian levels, and tariff policy has no substantive role.

In the relatively unconstrained world of Propositions 1 and 2, there is thus an alignment of instruments with objectives that is straightforward and as expected: with international transfers dealing with distributional concerns, carbon taxes are addressed to the climate externality and tariffs - except in so far as they may be needed to substitute for explicit transfers-are redundant. Importantly for present purposes, there is nothing in Propositions 1 and 2 that is in the nature of a border tax adjustment: no sign, that is, of the efficient tariff in any country reflecting the difference between its own carbon tax and that of the other countries. ${ }^{17}$ A case for BTA can thus arise only in more constrained circumstances, and it is this possibility that we now turn.

\section{Pareto efficiency AND the Role OF border tax ADJUSTMENTS}

Imagine then that for some reason-perhaps unmodeled political constraints-not all carbon taxes and tariffs are freely variable. Specifically, suppose-going to something of the opposite extreme to the circumstances of the previous section-that they can be freely set in country $h$ but everywhere else are fixed at arbitrary levels. We refer to these countries as 'unconstrained' and 'constrained' respectively (and occasionally to $h$ as 'home'), and will have in mind in the informal discussion that carbon taxes in the latter-which may be sector-specific-are 'too low' (relative to the first-best Pigovian carbon-tax). The global economy is thus constrained ${ }^{18}$ inside the global utility possibility frontier, and the question is: how should carbon taxes and tariffs then be set in country $h$ ?

For clarity, it is useful to approach this in two steps. Subsection A. deals first with the case in which distributional issues can be dealt with by international lump-sum transfers. This,

\footnotetext{
${ }^{17}$ In the latter case, of course, there is simply no difference in carbon taxes.

${ }^{18}$ Leaving aside the case in which the arbitrary rates in all unconstrained countries happen to coincide with those of some Pareto efficient allocation.
} 
together with further standard simplifying assumptions, gives rise to some sharp results. Subsection B. then turns to the more general and complex case.

\section{A. Border tax adjustments in the absence of distributional concerns}

It is useful to start with the relatively simple case, which gives a sharp result upon which some intuition can be built.

Proposition 3 Suppose there are only two countries, 1 and 2, with carbon taxes and tariffs fixed at arbitrary levels in country 2 but unconstrained in country 1, that lump sum transfers between the two countries are unconstrained and that compensated demands for the non-numeraire commodities are independent of emissions ( so that $\mathbf{e}_{\mathbf{p} k}^{j}=\mathbf{0}_{(N-1) \times 1}$ ). Then Pareto efficiency requires that:

(a) Carbon taxes in the unconstrained country 1 satisfy

$$
\mathbf{s}^{1 \prime}=\left(\sum_{j=1}^{2} e_{k}^{j}\right) \boldsymbol{\iota}^{\prime}
$$

and

(b) tariffs in country 1 satisfy

$$
\boldsymbol{\tau}^{1 \prime}=\tau^{2 \prime}+\left(\mathbf{s}^{1}-\mathbf{s}^{2}\right)^{\prime} \mathbf{r}_{\mathbf{s p}}^{2}\left(\mathbf{e}_{\mathbf{p p}}^{2}-\mathbf{r}_{\mathbf{p p}}^{2}\right)^{-1}
$$

Proof: The proof follows from Proposition 5 below by setting $\sigma^{j}=\sigma$ and $\mathbf{e}_{\mathbf{p} k}^{j}=\mathbf{0}_{(N-1) \times 1}$ for all $j$.

Now, and in the absence of emission effects through compensated demands (something we return to shortly below), the Pigovian tax is set at its first-best Pigovian level. The unconstrained tariff $\tau^{1}$ in (13) is doing two things. First, it is neutralizing the potential production inefficiency induced by the constrained tariff abroad: setting $\tau^{1}=\tau^{2}$ ensures that producer prices in the two countries coincide. Second-and of most interest here-it is reflecting the difference in carbon taxes between the two countries, differing from zero only to the extent that the carbon tax abroad is not set at its first best level. This latter element of the Pareto efficient tariff is thus a form of border tax adjustment.

The nature of the BTA called for in Proposition 3 is though somewhat complex, reflecting the impact of carbon prices on emissions in the constrained country (through ${ }^{19} \mathbf{r}_{\mathrm{sp}}^{2}$ ) and the price

\footnotetext{
${ }^{19}$ This is Copeland's (1994) indicator of sectoral pollution intensity. The point here is also closely related to the observation of Lockwood and Whalley (2010) that a case for BTA can arise only when differential carbon taxes affect relative producer prices: otherwise the exchange rate (or domestic price level) will accommodate such differences automatically.
} 
elasticity of net imports there. This, incidentally, provides an answer to one question that has lingered in the literature: whether the border tax adjustment should reflect technology in the adjusting country, abroad, or some mixture of the two: Proposition 3 shows that constrained Pareto efficiency requires that adjustment (both the tariff on imports and the refund on exports) be by the latter. Indeed, if $\mathbf{r}_{\mathbf{s p}}^{2}=\mathbf{0}_{N \times(N-1)}$, so that there is no possibility of affecting emissions in the constrained country by manipulating producer prices there, the cooperative case for BTA vanishes.

To see the intuition underlying the form of BTA called for in part (b) of Proposition 3, suppose for simplicity that (in addition to the assumptions of the proposition) all carbon taxes and tariffs are zero in the constrained country, 2. Recalling that optimality requires that any conceivable marginal changes in policy have zero impact (given the availability of international transfers) on the sum of utilities, consider the particular policy of combining a change in world prices, and hence of producer prices in the constrained country, of $\mathbf{d w}=\mathbf{d} \mathbf{p}^{2}$, with an offsetting change in the unconstrained tariff, $\mathbf{d} \tau^{1}=-\mathbf{d w}$. It can then be shown (assuming for simplicity that $\mathbf{e}_{\mathbf{p} u}^{2}=\mathbf{e}_{\mathbf{p} k}^{2}=\mathbf{0}_{(N-1) \times 1}$ ), since producer prices (and the carbon tax) in the unconstrained country are unchanged, that the consequent change in global welfare is

$$
e_{u}^{1} d u^{1}+e_{u}^{2} d u^{2}=-\left[\left(e_{k}^{1}+e_{k}^{2}\right) d k+\tau^{1 \prime}\left(\mathbf{e}_{\mathbf{p p}}^{2}-\mathbf{r}_{\mathbf{p p}}^{2}\right)\right] \mathbf{d p}^{2}
$$

The first effect in (14) is simply the global social benefit of any reduction in country 2's emissions induced by the change in producer prices there. The second term is $-\tau^{1 \prime}\left(\mathbf{e}_{\mathbf{p p}}^{2}-\mathbf{r}_{\mathbf{p p}}^{2}\right)=-\tau^{1 \prime} \mathbf{d m}^{2}$, which in turn is equal, in equilibrium, to $\tau^{1 \prime} \mathbf{d m}^{1}$; this effect, reflecting the impact of the reform on the distortion of trade implied by the initial tariff structure, is thus harmful to the extent that it decreases 1's imports of goods that are subject to a positive tariff. Optimal policy implies balancing these two effects; which, since $d k=-\iota^{\prime} \mathbf{r}_{\mathbf{s p}}^{2} \mathbf{d} \mathbf{p}^{2}$, requires

$$
\boldsymbol{\tau}^{1 \prime}=\left(e_{k}^{1}+e_{k}^{2}\right) \boldsymbol{\iota}^{\prime} \mathbf{r}_{\mathbf{s p}}^{2}\left(\mathbf{e}_{\mathbf{p p}}^{2}-\mathbf{r}_{\mathbf{p p}}^{2}\right)^{-1},
$$

which, recalling part (a) of Proposition 3, is precisely as part (b) implies in this case. The kind of policy this implies is a reduction in the producer price of 'dirty' goods in the constrained country, to discourage their production there, combined with - indeed induced by - a tariff that offsets the tendency for the unconstrained country to consequently import more of those dirty goods.

A more direct piece of intuition may also be helpful. Continuing the story of the previous paragraph, suppose that country 2 now sets its carbon tax at the Pigovian level. If, in response, tariffs in country 1 are eliminated - as part (b) of Proposition 3 requires - and world prices adjusted to leave prices $\mathbf{p}$ unchanged, then the change in country 2's exports (to a linear 
approximation $\left.^{20}\right)$ is

$$
\mathbf{d m}^{2 \prime}=\boldsymbol{\tau}^{1 \prime}\left(\mathbf{e}_{\mathbf{p p}}^{2}-\mathbf{r}_{\mathbf{p p}}^{2}\right)-\left(e_{k}^{1}+e_{k}^{2}\right) \boldsymbol{\iota}^{\prime} \mathbf{r}_{\mathbf{s p}}^{2} .
$$

But (15) implies that $\mathbf{d m}^{2}=\mathbf{0}_{(N-1) \times 1}$. That is, a collective policy response consistent with Proposition 3 leaves country 2's exports (roughly) unaffected. Turning the point the other way: the collectively efficient tariff policy undoes (to a first approximation) the trade impact of any country setting its carbon taxes away from the Pigovian level.

While Proposition 3 calls for what is recognizably a form of BTA-conditioning the unconstrained tariff directly on the difference in carbon tax rates between the two countries-it is substantially more complex than the type of BTA envisaged in practical discussions. As noted above, in principle it is necessary to adjust the difference in carbon taxes to reflect the elasticities of output with respect to carbon taxes abroad and the price elasticities of foreign import. In practice, what is commonly in mind is a more mechanical calculation (perhaps the only type with any hope of verifiability) of charging imports (and refunding on exports) an amount equal to the shortfall of the carbon tax actually paid abroad, directly and indirectly, relative to that which would have been paid had the home country carbon tax been applied. To express this in the present notation denote by $\mathbf{B}^{2}(\mathbf{p}, \mathbf{s})$ the $N \times(N-1)$ matrix whose typical element $b_{n k}$ denotes the production of non-numeraire good $k$ required, in country 2, per unit of output of good $n,{ }^{21}$ and by $\boldsymbol{\Phi}^{2}$ the $N \times N$ diagonal matrix whose element $\phi_{n}$ gives carbon emissions per unit of gross output (assumed constant). Then the mechanical BTA just described corresponds to the vector

$$
\gamma^{\prime}=\left(\mathbf{s}^{1}-\mathbf{s}^{2}\right)^{\prime} \mathbf{\Phi}^{2} \mathbf{B}^{2}\left(\mathbf{p}^{2}\right)
$$

whose elements give the amount by which the carbon tax paid per unit of output in country 2 falls short of that which would have been paid, given the production techniques used in country 2 , had the carbon tax rates of country 1 been applied.

To relate this to the more complex form of BTA called for by Proposition 3, write emissions in country 2 as

$$
\mathbf{z}^{2}=-\mathbf{r}_{s}^{2}=\boldsymbol{\Phi}^{2} \mathbf{B}^{2}(\mathbf{p}, \mathbf{s}) \mathbf{r}_{\mathbf{p}}^{2}(\mathbf{p}, \mathbf{s})
$$

Assuming emissions per unit of output to be constant, differentiating (18)—using Proposition 93 of Dhyrmes (1978)—gives

$$
-\mathbf{r}_{\mathbf{s p}}^{2}=\boldsymbol{\Phi}\left[\mathbf{B}^{2} \mathbf{r}_{\mathbf{p p}}^{2}+\Delta \mathbf{B}_{\mathbf{p}}^{2}\right]
$$

\footnotetext{
${ }^{20}$ And maintaining the temporary assumption that $\mathbf{e}_{\mathbf{p} u}^{2}=\mathbf{e}_{\mathbf{p} k}^{2}=\mathbf{0}_{(N-1) \times 1}$.

${ }^{21}$ In perhaps more familiar terms, $\mathbf{B}=\left(\mathbf{I}_{N}-\mathbf{A}\right)^{-1}$ where $\alpha_{n k}$ denotes the input of good $n$ required per unit of gross output of $k$.
} 
where $\Delta^{2} \equiv \mathbf{r}_{\mathbf{p}}^{2 \prime} \otimes \mathbf{I}_{N}$ and $\mathbf{B}_{\mathbf{p}}^{2}=\partial \operatorname{vec}(\mathbf{B}) / \partial \mathbf{p}$. Substituting (19) into (13) and recalling (17), the BTA of Proposition 3 can then also be written as

$$
\tau^{1 \prime}=\tau^{2 \prime}-\left(\mathbf{s}^{1}-\mathbf{s}^{2}\right)^{\prime} \mathbf{\Phi}^{2}\left[\mathbf{B}^{2} \mathbf{e}_{\mathbf{p p}}^{2} \Delta^{2}+\mathbf{B}_{\mathbf{p}}^{2}\right]\left(\mathbf{e}_{\mathbf{p p}}^{2}-\mathbf{r}_{\mathbf{p p}}^{2}\right)^{-1}
$$

The constrained Pareto-efficient BTA thus requires two adjustments to the mechanical form of BTA based on technology abroad, to allow for the impact on emissions that a change in prices abroad may have through changes in both patterns of input use (through $\mathbf{B}_{\mathbf{p}}^{2}$ ) and/or demand (through $\mathbf{e}_{\mathbf{p p}}^{2}$ ).

It follows immediately from (20) that:

Proposition 4 In the circumstances of Proposition 3, if emissions per unit of output are constant, there are no substitution effects in demand between non-numeraire commodities $\left(\mathbf{e}_{\mathbf{p p}}^{2}=\mathbf{0}_{(N-1) \times(N-1)}\right)$, and required inputs of goods per unit of output are fixed $\left(\mathbf{B}_{\mathbf{p}}^{2}=\mathbf{0}_{N(N-1) \times(N-1)}\right)$ then Pareto efficiency requires that:

$$
\tau^{1}=\tau^{2}+\gamma
$$

Here then is a case in which collectively efficient policy has a remarkably simple form. The unconstrained carbon tax should be set at the first-best Pigovian level, and, of particular interest in the present context, border tax adjustment should take the form of a countervailing charge on imports (and refund on exports) corresponding mechanically to the tax 'under-paid' in the foreign country. One important difference from common proposals, however, is that, to the extent that technologies differ between the two countries, the rebate on exports will generally not equal the carbon tax paid at home.

Proposition 4 rests on simplifying assumptions. It does suggest, nevertheless, that—conceptually at least—proposals for border adjusting carbon taxes commonly encountered in policy discussion are not wholly misplaced, even from the perspective of global rather than national welfare. Things are, of course, more complicated under the more general conditions of Proposition 2, taken up next.

\section{B. Border tax adjustments in the general case}

Reverting to the general case in which explicit international transfers cannot be deployed, there are many countries and pollution affects commodity demand, efficient carbon tax and tariff structures are substantially more complex:

Proposition 5 Suppose that carbon taxes and tariffs are freely variable in country h but maybe constrained elsewhere. Then, at any constrained Pareto efficient allocation: 
(a) Carbon taxes in h are given by

$$
\sigma^{h} \mathbf{s}^{h \prime}=\left\{\sum_{j=1}^{J} \sigma^{j} e_{k}^{j}+\sum_{j \neq h}^{J}\left(\sigma^{h} \boldsymbol{\tau}^{h}-\sigma^{j} \boldsymbol{\tau}^{j}\right)^{\prime} \mathbf{e}_{\mathbf{p} k}^{j}\right\} \boldsymbol{\iota}^{\prime},
$$

and

(b) tariffs are such that

$$
\begin{aligned}
\sigma^{h} \boldsymbol{\tau}^{h \prime}= & -\sum_{j=1}^{J} \sigma^{j} \mathbf{m}^{j \prime}\left(\mathbf{Q}^{h}\right)^{-1}+\sum_{j \neq h}^{J} \sigma^{j} \boldsymbol{\tau}^{j \prime} \mathbf{m}_{\mathbf{p}}^{j}\left(\mathbf{Q}^{h}\right)^{-1} \\
& +\sum_{j \neq h}^{J}\left(\sigma^{h} \mathbf{s}^{h}-\sigma^{j} \mathbf{s}^{j}\right)^{\prime} \mathbf{r}_{\mathbf{s p}}^{j}\left(\mathbf{Q}^{h}\right)^{-1}
\end{aligned}
$$

where $\mathbf{Q}^{h} \equiv \sum_{j \neq h}^{J} \mathbf{m}_{\mathbf{p}}^{j}$

Proof: See Appendix D.

Part (a) of Proposition 5 shows, in contrast to Proposition 1, that the unconstrained carbon tax in country $h$ is not set equal to the global welfare-weighted marginal damage from emissions. This is because the carbon tax set in $h$, by affecting emissions and hence demand structures in the constrained countries, impacts distortions associated with the tariffs set there. To the extent, for instance, that the fall in emissions implied by increasing the carbon tax in $h$ increases demand in some constrained country $j$ of goods that tariff distortions imply are under-imported there (the tariff imposed by country $j$ being lower than any export subsidy imposed by country $h$ ), so that $\left(\sigma^{h} \tau^{h}-\sigma^{j} \boldsymbol{\tau}^{j}\right)^{\prime} \mathbf{e}_{\mathbf{p} k}^{j} \boldsymbol{\iota}^{\prime}>\mathbf{0}_{1 \times N}^{\prime}$, this calls for $\mathbf{s}^{h}$ to be set higher than would otherwise be the case. In this way, the unconstrained carbon tax is used to reduce the distortions associated with imperfections of collective tariff policies. If, for example, a warming in climate leads in country $j$ to increased demand for heating equipment that is subject to a large import tariff, this becomes an argument for a higher carbon tax in country $h$.

One other aspect of part (a) bears emphasis: since $\mathbf{s}^{h}$ is collinear with $\boldsymbol{\iota}$, the carbon tax in the unconstrained country $h$ should be uniform across sectors, whether or not it is uniform in the constrained countries. The best way to respond, if need be, to sectoral differentiation abroad, is through the tariff structure. The proper task of the carbon tax is to address inefficiencies in the aggregate level of emissions.

Part (b), characterizing Pareto efficient tariff design in country $j$, is still more complex, with four effects at work. The first term relates to the distributional effects of terms of trade effect associated with varying tariffs in country $h$ (vanishing if international lump sum transfers can be deployed) and the second to the interaction with tariffs distortions abroad. Of most interest here is the final term, $\sum_{j \neq h}^{J}\left(\sigma^{h} \mathbf{s}^{h}-\sigma^{j} \mathbf{s}^{j}\right)^{\prime} \mathbf{r}_{\mathbf{s p}}^{j}\left(\mathbf{Q}^{h}\right)^{-1}$. This is a BTA in the broad sense defined in the introduction and discussed after Proposition 3, but now with carbon taxes weighted by 
income neediness, $\sigma^{j}$. Loosely speaking, in the absence of international transfers constrained Pareto efficiency requires pretending that poorer countries have higher carbon taxes than is actually the case.

There is no entirely sharp targeting of instruments to objectives in Proposition 5: when international transfers cannot be made, tariff and carbon tax policies become closely intertwined. There are, nevertheless fairly clearly-defined rules for the two. Carbon taxes are addressed to global climate change and an interaction through demand effect, with tariff distortions; and tariffs are set with an eye partly to BTA, along the lines discussed above, and partly to addressing equity concerns by engineering judicious movements in terms of trade.

\section{Further discussion}

This section compares the results above to those of Markusen (1975) for the non-cooperative case and asks how the case for BTA is affected when countries use not carbon taxes but cap and trade systems.

\section{A. Comparison with non-cooperative policies}

While the focus of this paper is on cooperative policy-making, the framework is sufficiently general to encompass the case in which the choice of carbon tax and tariff policies of country $h$ are motivated by national interest (as in, for example, Markusen (1975)). This can be done-taking again country $h$ to be the unconstrained country-simply by setting $\sigma^{j}=0$ for all $j \neq h$ in Proposition 5 (as a simple device for attaching no welfare weight to countries other than $h$ ). Doing so brings out how the results above differ from and build on earlier analyses of the non-cooperative case. Proceeding in this way, Proposition 5 implies that carbon taxes satisfy

$$
\mathbf{s}^{h \prime}=e_{k}^{h} \boldsymbol{\iota}^{\prime}+\tau^{h \prime} \sum_{l \neq h}^{J} \mathbf{e}_{\mathbf{p} k}^{l} \boldsymbol{\iota}^{\prime},
$$

and tariff policies are set such that

$$
\boldsymbol{\tau}^{h \prime}=\left[-\mathbf{m}^{h \prime}+e_{k}^{h} \sum_{l \neq h}^{J}\left(\iota^{\prime} \mathbf{r}_{\mathbf{s p}}^{l}\right)\right]\left(\mathbf{Q}^{h}\right)^{-1}
$$

Equations (24) and (25) are the many-country counterparts of Markusen (1975)—see, in particular, his equation (15). Clearly, a unilateral response of country $h$ (to carbon pricing and tariff policies in other countries) differs from the cooperative one, as one might expect, in two ways: carbon taxes now reflect only national damage, not global, and tariffs are set in part with a view to standard optimal tariff considerations. 


\section{B. Border tax adjustment and cap-and-trade}

It has been assumed so far that the climate instruments deployed, if any, are carbon taxes. An alternative, however, is cap-and trade: not levying a charge directly on emissions, but instead issuing a fixed number of tradable emission rights. This alternative is of considerable practical importance, perhaps even more so than carbon taxation: it is schemes of this kind that have been adopted by the EU and which have made most headway in the U.S. The question then is whether the conclusions above continue to apply when the instrument of climate policy is not tax, but national-level cap-and-trade.

The essence of the results in Section III-when instrument choice is unconstrained-clearly apply essentially unchanged. This is a simple consequence of the familiar equivalence, under perfect certainty (as assumed here) of carbon taxation and cap-and-trade, ${ }^{22}$ and of the result above that sectoral differentiation of carbon taxation (which could not be replicated by permits tradable between sectors) cannot be part of a Pareto-efficient allocation: analogues of Propositions 1 and 2 thus hold with the characterizations of carbon taxes reinterpreted as characterizing emissions caps in terms of the associated shadow value of emissions. (Whether the pollution permits are auctioned or allocated free of charge, critical in practice, is immaterial here, given the lump sum return of any revenues raised).

What though if, as in the earlier discussion, the instrument choice is constrained in some country? For brevity, again assume, as in Subsection IV.A, just two countries, with lump-sum transfers between them available. ${ }^{23}$ The critical question then is whether the constrained countries use carbon taxation or cap-and-trade.

If the constrained country uses carbon taxation, Propositions 3-5 continue to apply even if the unconstrained uses cap-and-trade, since any allocation that can be achieved when it uses carbon taxation - as above — can be replicated by instead fixing the corresponding level of domestic emissions as the cap in a trading scheme.

Matters are very different, however, if the constrained country uses cap-and-trade. For then policies adopted in the unconstrained country can have no impact on emissions in the constrained country. ${ }^{24}$ Since the sole rationale of BTA in the cooperative case is to manipulate

\footnotetext{
${ }^{22}$ There is large literature on the choice between taxation and cap-and-trade under uncertainty: see, for instance, Pizer (2002) and Aldy et al. (2010).

${ }^{23}$ We omit proofs of the claims that follow: these are straightforward once the structure of Section 2 is reformulated in terms of emission levels rather than carbon taxes.

${ }^{24}$ So long, that is, as the emission cap there is binding. It could in principle be that in some efficient allocations the unconstrained country sets its tariffs so as to drive emissions abroad below the cap. In that case, the situation in the constrained country is the same, at the margin, as if it set a carbon tax of zero; and so the earlier results for that case apply.
} 
emissions in the constrained country, it can in this case serve no purpose. The point that quantity restrictions in one country powerfully affect the implications of trade reform in others is a familiar one: see for instance Copeland and Taylor (2005, pp. 123), Falvey (1988) and, closest to the present context, Copeland (1994). The implications do not seem to have been recognized, however, in the context of BTAs: the collective case for such adjustment depends not only on the level of carbon prices abroad but also on the way in which any carbon pricing there is implemented.

\section{Concluding Remarks}

This paper has explored the interplay between climate- and trade-related instruments in forming globally efficient responses to climate change. One role that emerges for tariff policies is in easing the constraints stemming from cross-country distributional concerns that can make non-uniform carbon pricing efficient. The other potential role, on which most of the analysis has focused, is in mitigating distortions that arise from cross-country differences in carbon prices. The paper has identified circumstances in which global efficiency does indeed require some form of BTA (and others in which it does not), and has characterized the form of adjustment needed.

The first role emerges most clearly when there are no constraints on the rates at which carbon taxes (or emission levels under cap-and-trade schemes) and tariffs can be set. The implications of Pareto-efficiency are then straightforward: carbon prices should be uniform across sectors within countries (or permits tradable across them), but equity considerations may call for them to be lower in countries judged less needy. The only possible role for tariffs is then as an indirect way to alleviate the underlying cross-country equity concerns that can warrant different carbon prices, a task quite different from that of responding to distortions arising from the differences in carbon prices.

The second role emerges when climate change policies are constrained in countries that deploy taxes (perhaps of zero). Global efficiency requires a more purposive use of tariff policy in recognition of climate concerns: a form of BTA. It remains optimal to set those carbon prices that can be set freely - whether explicitly by taxation or implicitly by cap-and-trade - in line with (a simple modification of) the Pigou rule (and not to differentiate them across sectors). But tariffs should now be set so as to recognize the impact on emissions of sourcing domestic demand from countries with carbon taxes that are inappropriate from the collective perspective. The results here fully characterize the BTA required. This, in general, requires weighting the shortfall in carbon taxes in the constrained country by the carbon-price responsiveness of outputs and price elasticity of exports there and, when international transfers cannot be deployed, treating poorer countries as if they had higher carbon taxes than is in fact the case. 
The analysis has also identified, however, one special but instructive case to which the required BTA takes the simple form — as envisaged in practical policy debate and proposals — of a charge on imports (and rebate on export) equal to the carbon tax 'not paid' abroad.

Importantly, this case for BTA does not apply if it is (binding) cap-and-trade policies, not carbon taxation, that is the constrained instrument. This is because emissions in such countries cannot then be affected by policies elsewhere. While there has been some discussion of the practical differences between implementing BTAs under carbon taxes and cap-and-trade, the wider point that the underlying economic case for adjustment is entirely different in the two cases - and much weaker under cap-and-trade — seems not to have been recognized. There may then be a case for BTA in terms of national self-interest; but in terms of collective efficiency there is not.

The analysis here is of course severely limited in several respects. Factors have been assumed immobile, for example, precluding the possibility of carbon leakage through location choices that is a major concern in policy debates. And implementation of any form of BTA in any event raises a host of legal and practical issues. What the analysis here does establish, however, is that while practical proposals are naturally driven primarily by national (or sectoral) self-interest, a strong conceptual case can be made for the use of BTAs along broadly the lines often proposed-in relation to carbon taxes, but not cap-and-trade-in the more appealing terms of global efficiency. 


\section{Appendix A: Necessary conditions for Pareto efficiency}

Perturbing (5), using (1), $\mathbf{p}^{j}=\mathbf{w}+\boldsymbol{\tau}^{j}$ and recalling that $\mathbf{r}_{\mathbf{s}}^{j}=-\mathbf{z}^{j}$, gives

$$
\lambda_{u}^{j} d u^{j}-\lambda_{\mathbf{w}}^{j \prime} \mathbf{d w}-\lambda_{\tau}^{j \prime} \mathbf{d} \tau^{j}-\sum_{i \neq j}^{J} \lambda_{\tau}^{j / i \prime} \mathbf{d} \tau^{i}-\lambda_{\mathbf{s}}^{j \prime} \mathbf{d} \mathbf{s}^{j}-\sum_{i \neq j}^{J} \lambda_{\mathbf{s}}^{j / i \prime} \mathbf{d} \mathbf{s}^{i}=0 \quad j=1, \ldots, J,
$$

where

$$
\begin{aligned}
\lambda_{u}^{j} & \equiv e_{u}^{j}-\boldsymbol{\tau}^{j \prime} \mathbf{e}_{\mathbf{p} u}^{j}, \\
-\lambda_{\mathbf{w}}^{j \prime} & \equiv \mathbf{m}^{j \prime}+\lambda_{k}^{j} \sum_{l=1}^{J}\left(-\iota^{\prime} \mathbf{r}_{\mathbf{s p}}^{l}\right)+\mathbf{s}^{j \prime} \mathbf{r}_{\mathbf{s p}}^{j}-\boldsymbol{\tau}^{j \prime} \mathbf{m}_{\mathbf{p}}^{j}, \\
-\lambda_{\tau}^{j \prime} & \equiv \lambda_{k}^{j}\left(-\boldsymbol{\iota}^{\prime} \mathbf{r}_{\mathbf{s p}}^{j}\right)+\mathbf{s}^{j \prime} \mathbf{r}_{\mathbf{s p}}^{j}-\boldsymbol{\tau}^{j \prime} \mathbf{m}_{\mathbf{p}}^{j}, \\
-\lambda_{\tau}^{j / i \prime} & \equiv \lambda_{k}^{j}\left(-\boldsymbol{\iota}^{\prime} \mathbf{r}_{\mathbf{s p}}^{i}\right) \\
-\lambda_{\mathbf{s}}^{j \prime} & \equiv \lambda_{k}^{j}\left(-\boldsymbol{\iota}^{\prime} \mathbf{r}_{\mathbf{s s}}^{j}\right)+\mathbf{s}^{j \prime} \mathbf{r}_{\mathbf{s s}}^{j}+\boldsymbol{\tau}^{j \prime} \mathbf{r}_{\mathbf{p s}}^{j}, \\
-\lambda_{\mathbf{s}}^{j / i \prime} & \equiv \lambda_{k}^{j}\left(-\boldsymbol{\iota}^{\prime} \mathbf{r}_{\mathbf{s s}}^{i}\right) \\
\lambda_{k}^{j} & =e_{k}^{j}-\boldsymbol{\tau}^{j} \mathbf{e}_{\mathbf{p} k}^{j},
\end{aligned}
$$

with (A.5) and (A.7) referring to the effects on country $j$ of changes in carbon taxes and tariffs in all other countries.

Perturbing equations (7) gives

$$
\sum_{j=1}^{J} \mathbf{e}_{\mathbf{p} u}^{j} d u^{j}=\pi_{\mathbf{p p}} \mathbf{d w}+\sum_{j=1}^{J} \pi_{\mathbf{p p}}^{j} d \tau^{j}+\sum_{j=1}^{J} \pi_{\mathbf{p s}}^{j} \mathbf{d} \mathbf{s}^{j},
$$

where

$$
\begin{aligned}
&-\boldsymbol{\pi}_{\mathbf{p p}} \equiv \sum_{j=1}^{J}\left\{\mathbf{m}_{\mathbf{p}}^{j}+\mathbf{e}_{\mathbf{p} k}^{j} \sum_{l=1}^{J}\left(-\boldsymbol{\iota}^{\prime} \mathbf{r}_{\mathbf{s p}}^{l}\right)\right\}, \\
&-\boldsymbol{\pi}_{\mathbf{p p}}^{j} \equiv \mathbf{m}_{\mathbf{p}}^{j}+\sum_{l=1}^{J} \mathbf{e}_{\mathbf{p} k}^{l}\left(-\boldsymbol{\iota}^{\prime} \mathbf{r}_{\mathbf{s p}}^{j}\right), \\
&-\boldsymbol{\pi}_{\mathbf{p s}}^{j} \equiv-\mathbf{r}_{\mathbf{p s}}^{j}+\sum_{l=1}^{J} \mathbf{e}_{\mathbf{p} k}^{l}\left(-\boldsymbol{\iota}^{\prime} \mathbf{r}_{\mathbf{s s}}^{j}\right) .
\end{aligned}
$$

Perturbing also (4) and stacking the results along with (A.1) for all countries $j$ and (A.9) gives the system

$$
\Lambda_{\mathbf{u}} \mathrm{du}-\Lambda_{\mathrm{w}} \mathbf{d w}-\Lambda_{\tau} \mathrm{d} \tau-\Lambda_{\mathrm{s}} \mathrm{ds}-\Lambda_{\alpha} \mathrm{d} \alpha=\mathbf{0}_{(J+2 N-1) \times 1},
$$


where the matrices $\Lambda_{u}, \Lambda_{w}, \Lambda_{\tau}, \Lambda_{s}$ are given by

$$
\begin{aligned}
& \boldsymbol{\Lambda}_{\mathbf{u}}=\left[\begin{array}{cccc}
\lambda_{u}^{1} & 0 & \cdots & 0 \\
0 & \lambda_{u}^{2} & \cdots & 0 \\
\vdots & \vdots & \ddots & \vdots \\
0 & 0 & \cdots & \lambda_{u}^{J} \\
\mathbf{e}_{\mathbf{p} u}^{1} & \mathbf{e}_{\mathbf{p} u}^{2} & \cdots & \mathbf{e}_{\mathbf{p} u}^{J}
\end{array}\right] \mathbf{d u}=\left[\begin{array}{c}
d u^{1} \\
d u^{2} \\
\vdots \\
d u^{J}
\end{array}\right] \\
& \boldsymbol{\Lambda}_{\mathbf{w}} \equiv\left[\begin{array}{c}
\lambda_{\mathbf{w}}^{1 \prime} \\
\vdots \\
\lambda_{\mathbf{w}}^{J \prime} \\
\boldsymbol{\pi}_{\mathbf{p p}} \\
\mathbf{0}_{N \times(N-1)}
\end{array}\right] \mathbf{d w} \equiv\left[\begin{array}{c}
d w_{2} \\
d w_{3} \\
\vdots \\
d w_{N}
\end{array}\right] \\
& \boldsymbol{\Lambda}_{\tau} \equiv\left[\begin{array}{cccc}
\lambda_{\tau}^{1 \prime} & \lambda_{\tau}^{1 / 2 \prime} & \cdots & \lambda_{\tau}^{1 / J \prime} \\
\lambda_{\tau}^{2 \prime 1 \prime} & \lambda_{\tau}^{2 \prime} & \cdots & \lambda_{\tau}^{2 / J \prime} \\
\vdots & \vdots & \ddots & \vdots \\
\lambda_{\tau}^{J / 1 \prime} & \lambda_{\tau}^{J / 2 \prime} & \cdots & \lambda_{\tau}^{J \prime} \\
\pi_{\mathbf{p p}}^{1} & \pi_{\mathbf{p p}}^{2} & \cdots & \pi_{\mathbf{p p}}^{J}
\end{array}\right] \mathbf{d} \tau=\left[\begin{array}{c}
\mathbf{d} \tau^{1} \\
\mathbf{d} \tau^{2} \\
\vdots \\
\mathbf{d} \tau^{J}
\end{array}\right] \\
& \mathbf{\Lambda}_{\mathbf{s}} \equiv\left[\begin{array}{cccc}
\lambda_{\mathbf{s}}^{1 \prime} & \lambda_{\mathbf{s}}^{1 / 2 \prime} & \cdots & \lambda_{\mathbf{s}}^{1 / J \prime} \\
\lambda_{\mathbf{s}}^{2 \prime 1 \prime} & \lambda_{\mathbf{s}}^{2 \prime} & \cdots & \lambda_{\mathbf{s}}^{2 / J \prime} \\
\vdots & \vdots & \ddots & \vdots \\
\lambda_{\mathbf{s}}^{J / 1 \prime} & \lambda_{\mathbf{s}}^{J / 2 \prime} & \cdots & \lambda_{\mathbf{s}}^{J \prime} \\
\pi_{\mathbf{p s}}^{1} & \pi_{\mathbf{p s}}^{2} & \cdots & \pi_{\mathbf{p s}}^{J}
\end{array}\right] \mathbf{d s} \equiv\left[\begin{array}{c}
\mathbf{d} \mathbf{s}^{1} \\
\mathbf{d s}^{2} \\
\vdots \\
\mathbf{d s}^{J}
\end{array}\right] \\
& \mathbf{\Lambda}_{\alpha} \equiv\left[\begin{array}{cccc}
-\mathbf{w}^{\prime} & \mathbf{0}^{\prime} & \cdots & \mathbf{0}^{\prime} \\
\mathbf{0}^{\prime} & -\mathbf{w}^{\prime} & \cdots & \mathbf{0} \\
\vdots & \vdots & \ddots & \vdots \\
\mathbf{0}^{\prime} & \mathbf{0}^{\prime} & \cdots & -\mathbf{w}^{\prime} \\
\overline{\mathbf{0}} & \overline{\mathbf{0}} & \overline{\mathbf{0}} & \overline{\mathbf{0}} \\
\mathbf{I}_{N} & \mathbf{I}_{N} & \cdots & \mathbf{I}_{N}
\end{array}\right] \mathbf{d} \boldsymbol{\alpha} \equiv\left[\begin{array}{c}
\mathbf{d} \boldsymbol{\alpha}^{1} \\
\mathbf{d} \boldsymbol{\alpha}^{2} \\
\vdots \\
\mathbf{d} \boldsymbol{\alpha}^{J}
\end{array}\right]
\end{aligned}
$$

Notice that $\boldsymbol{\Lambda}_{\mathbf{u}}$ is of dimension $(J+2 N-1) \times J, \boldsymbol{\Lambda}_{\mathbf{w}}$ of dimension $(J+2 N-1) \times(N-1), \boldsymbol{\Lambda}_{\tau}$ of $(J+2 N-1) \times J(N-1), \boldsymbol{\Lambda}_{\mathbf{s}}$ of dimension $(J+2 N-1) \times J N$ and $\boldsymbol{\Lambda}_{\alpha}$ of dimension $(J+2 N-1) \times J N$.

The analysis that follows uses Motzkin's theorem of the alternative, which states (Mangasarian (1969), p.29)) that for a system of the form in (A.13) either there exists $\mathbf{d u} \geq \mathbf{0}_{J \times 1}$ and $\mathbf{d w}$ such that $\boldsymbol{\Lambda}_{\mathbf{u}} \mathbf{d u}+\mathbf{D d x}=\mathbf{0}$ or there exists $\mathbf{y}$ such that

$$
\begin{aligned}
\mathbf{y}^{\prime} \boldsymbol{\Lambda}_{\mathbf{u}} & \gg \mathbf{0}_{1 \times J}^{\prime}, \\
\mathbf{y}^{\prime} \mathbf{D} & =\mathbf{0}^{\prime} .
\end{aligned}
$$

The focus is thus on solutions to necessary conditions for Pareto-efficiency of the form 
$\mathbf{y}^{\prime} \mathbf{D}^{*}=\mathbf{0}^{\prime}$ where $\mathbf{D}^{*}$ is the submatrix of $\mathbf{D}$ corresponding to whichever of the instruments in $\mathbf{d x}$ may be deployed. For this is helpful to partition the vector $\mathbf{y}^{\prime}=\left(\boldsymbol{\sigma}^{\prime}, \mathbf{v}^{\prime}, \omega^{\prime}\right)$ conformably with the block structure of the matrices in (A.13). Starting from a tight equilibrium, it is required $\sigma \gg \mathbf{0}_{J \times 1}$.

\section{Appendix B: Proof of Proposition 1}

With $\mathbf{w}, \tau$ and $\mathbf{s}$ freely available, the conditions $\mathbf{y}^{\prime} \boldsymbol{\Lambda}_{\mathbf{w}}=\mathbf{0}^{\prime}, \mathbf{y}^{\prime} \boldsymbol{\Lambda}_{\tau}=\mathbf{0}^{\prime}$ and $\mathbf{y}^{\prime} \boldsymbol{\Lambda}_{\mathbf{s}}=\mathbf{0}^{\prime}$ imply, respectively, that

$$
\begin{aligned}
& \sum_{j=1}^{J} \sigma^{j}\left\{\mathbf{m}^{j \prime}+\lambda_{k}^{j} \sum_{l=1}^{J}\left(-\boldsymbol{\iota}^{\prime} \mathbf{r}_{\mathbf{s p}}^{l}\right)+\mathbf{s}^{j \prime} \mathbf{r}_{\mathbf{s p}}^{j}-\tau^{j \prime} \mathbf{m}_{\mathbf{p}}^{j}\right\}+\mathbf{v}^{\prime}\left\{\sum_{j=1}^{J}\left[\mathbf{m}_{\mathbf{p}}^{j}+\mathbf{e}_{\mathbf{p} k}^{j} \sum_{l=1}^{J}\left(-\boldsymbol{\iota}^{\prime} \mathbf{r}_{\mathbf{s p}}^{l}\right)\right]\right\} \\
& =\mathbf{0}_{1 \times(N-1)}^{\prime} \text {, } \\
& \sigma^{j}\left\{\lambda_{k}^{j}\left(-\boldsymbol{\iota}^{\prime} \mathbf{r}_{\mathbf{s p}}^{j}\right)+\mathbf{s}^{j \prime} \mathbf{r}_{\mathbf{s p}}^{j}-\tau^{j \prime} \mathbf{m}_{\mathbf{p}}^{j}\right\}+\sum_{l \neq j}^{J} \sigma^{l} \lambda_{k}^{l}\left(-\boldsymbol{\iota}^{\prime} \mathbf{r}_{\mathbf{s p}}^{j}\right)+\mathbf{v}^{\prime}\left\{\mathbf{m}_{\mathbf{p}}^{j}+\sum_{l=1}^{J} \mathbf{e}_{\mathbf{p} k}^{l}\left(-\boldsymbol{\iota}^{\prime} \mathbf{r}_{\mathbf{s p}}^{j}\right)\right\} \\
& =\mathbf{0}_{1 \times(N-1)}^{\prime}, j=1, \ldots J \text {, } \\
& \sigma^{j}\left\{\lambda_{k}^{j}\left(-\iota^{\prime} \mathbf{r}_{\mathbf{s s}}^{j}\right)+\mathbf{s}^{j \prime} \mathbf{r}_{\mathbf{s s}}^{j}+\tau^{j \prime} \mathbf{r}_{\mathbf{p s}}^{j}\right\}+\sum_{l \neq j}^{J} \sigma^{l} \lambda_{k}^{l}\left(-\boldsymbol{\iota}^{\prime} \mathbf{r}_{\mathbf{s s}}^{j}\right)+\mathbf{v}^{\prime}\left\{-\mathbf{r}_{\mathbf{p s}}^{j}+\sum_{l=1}^{J} \mathbf{e}_{\mathbf{p} k}^{l}\left(-\boldsymbol{\iota}^{\prime} \mathbf{r}_{\mathbf{s s}}^{j}\right)\right\} \\
& =\mathbf{0}_{1 \times N}^{\prime}, j=1, \ldots J \text {. }
\end{aligned}
$$

Post-multiplying (B.3) by $\left(\mathbf{r}_{\mathbf{s s}}^{j}\right)^{-1} \mathbf{r}_{\mathbf{s p}}^{j}$ and comparing the result with left-hand-side of (B.2), using also the definitions in (A.4)-A.7), non-singularity of $\mathbf{m}_{\mathbf{p}}^{j}$ implies that

$$
\sigma^{j} \boldsymbol{\tau}^{j}=\mathbf{v}, \quad j=1, \ldots J .
$$

from which part (b) of the proposition follows. Part (a) follows on using (B.4) and (A.8) in (B.3). Finally, (A.15) implies, recalling (A.2), that

$$
\sigma^{j}\left(e_{u}^{j}-\tau^{j \prime} \mathbf{e}_{\mathbf{p u}}^{j}\right)+\mathbf{v}^{\prime} \mathbf{e}_{\mathbf{p u}}^{j}>0, \quad j=1, \ldots J
$$

and hence, from (B.4), $\sigma^{j}>0, j=1, \ldots J$.

\section{Appendix C: Proof of Proposition 2}

It suffices to show that in either of the circumstances envisaged in the proposition

$$
\sigma^{j}=\sigma, j=1, \ldots J
$$

Starting with the case in which explicit lump-sum transfers are available the condition $\mathbf{y}^{\prime} \boldsymbol{\Lambda}_{\alpha}=\mathbf{0}_{1 \times J(N-1)}^{\prime}$ implies (C.1). Part (a) then follows directly from part (a) of Proposition 1, and part (b) from noting that (again from part (b) of Proposition 1) with $\tau^{j}=\tau, j=1, \ldots J$, the common tariff vector can be normalized to zero.

When explicit transfers are unavailable, using (B.4) and (A.2) in the condition $\mathbf{y}^{\prime} \boldsymbol{\Lambda}_{\mathbf{w}}=\mathbf{0}_{1 \times(N-1)}^{\prime}$ gives 


$$
\sum_{j=1}^{J} \sigma^{j}\left\{\mathbf{m}^{j \prime}+e_{k}^{j} \sum_{l=1}^{J}\left(-\iota^{\prime} \mathbf{r}_{\mathbf{s p}}^{l}\right)+\mathbf{s}^{j \prime} \mathbf{r}_{\mathbf{s p}}^{j}\right\}=\mathbf{0}_{1 \times(N-1)}^{\prime},
$$

which, using part (a) of the proposition, becomes

$$
\mathbf{M}^{\prime} \boldsymbol{\sigma}=\mathbf{0}_{(N-1) \times 1},
$$

where

$$
\mathbf{M}^{\prime}=\left[\begin{array}{llll}
\mathbf{m}^{1} & \mathbf{m}^{2} & \cdots & \mathbf{m}^{J}
\end{array}\right]_{(N-1) \times J} .
$$

Recall, from (7), that market clearing implies $\mathbf{M}^{\prime} \iota_{J}=\mathbf{0}_{N-1}$, so that $\mathbf{M}^{\prime}$ has column rank of no more that $J-1$. If it has precisely this rank, then $\sigma_{J \times 1}$ must be collinear with $\iota_{J \times 1}$ implying again that $\sigma^{j}=\sigma$, for $j=1, \ldots, J$.

\section{Appendix D: Proof of Proposition 5}

In this case, with countries other than $h$ constrained, conditions (B.2) and (B.3) can be assumed to hold only for $j=h$. Proceeding as in the proof of Proposition 1 gives

$$
\sigma^{h} \tau^{h}=\mathbf{v}
$$

Using this and (A.2) in (B.3) for $j=h$, part (a) follows. Using part (a) and (A.2) in (B.1) gives part (b). 


\section{REFERENCES}

Aldy, J., A. Krupnick, R. Newell, I. Parry, and W. Pizer. (2010). 'Designing climate change mitigation policy,' Journal of Economic Literature 48, 903-934.

Baumol, W.J., and W. Oates. (1988). The theory of environmental policy, 2nd edn, Cambridge University Press, Cambridge.

Chichilnisky, G., and G. Heal. (1994). 'Who should abate carbon emissions?: An international viewpoint,' Economics Letter 44, 443-449.

Copeland, B. (1994). 'International trade and the environment: Policy reform in a polluted small open economy,' Journal of Environmental Economics and Management 26, 44-65.

Copeland, B. (1996). 'Pollution content tariffs, environmental rent shifting, and the control of cross-border pollution,' Journal of International Economics 40, 459-476.

Copeland, B., and S. Taylor. (2004). 'Trade, growth, and the environment,' Journal of Economic Literature 42, 7-71.

Copeland, B., and S. Taylor. (2005). Trade and the environment: Theory and evidence, Princeton University Press.

Dixit, A., and V. Norman. (1980). Theory of international trade, Cambridge University Press.

Dhyrmes, P. (1978). Introductory econometrics, Springer-Verlag New York.

Falvey, R. (1988). 'Tariffs, quotas and piecemeal policy reform,' Journal of International Economics 25, 177-183.

Gros, D. (2009). 'Global welfare implications of carbon border taxes,' CESIfo Working Paper No. 2790.

Hoel, M. (1996). 'Should a carbon tax be differentiated across sectors?', Journal of Public Economics 59, 17-32.

Houser, T., R. Bradley, B. Childs, J. Werksman, and R. Heilmayr. (2008). 'Leveling the carbon playing field: International competition and U.S. climate policy design', Washington: Petersen Institute.

Keen, M. J., and D. Wildasin. (2004). 'Pareto-efficient international taxation,' American Economic Review 94, 259-275.

Kotsogiannis, C., and A. Woodland. (2012). 'Climate and international trade policies when emissions affect production possibilities,' mimeo, University of Exeter.

Levinson, A., and S. Taylor. (2008). 'Unmasking the pollution heaven effect,' International Economic Review 49, 223-254.

Lockwood B., and J. Whalley. (2010). 'Carbon-motivated border tax adjustments: Old wine in green bottles?' World Development, 810-819.

Mangasarian, O. (1969). Nonlinear programming. New York: McGraw-Hill. 
Markusen, J. (1975). 'International externalities and optimal tax structures,' Journal of International Economics 5, 15-29.

McLure, C. (2011). 'The GATT legality of border tax adjustments for carbon taxes and the cost of emissions permits: A riddle wrapped in a mystery inside an enigma,' Florida Tax Law Review 11, 221-294.

Moore, M. O. (2010). 'Implementing carbon tariffs: A fool's errand?', World Bank Policy Research Paper 5359.

Neary, J. (2006). 'International trade and the environment: Theoretical and policy linkages,' Environmental and Resource Economics 33(1), 95-118.

Obsterghaus, D., and C. Reif. (2010). 'Total costs and budgetary effects of adaptation to climate change: An assessment for the European Union,' CESIfo Working Paper No. 3143.

Organisation for Economic Cooperation and Development (2004). The political economy of environmentally related taxes. Paris: OECD.

Pizer, W. (2002). 'Combining price and control to mitigate global climate change,' Journal of Public Economics 85, 409-434.

Sandmo, A. (2005). 'Environmental taxation and revenue for development,' in A. B. Atkinson (ed.), New Sources of Development Finance. Oxford: Oxford University Press, 33-57.

Sandmo, A. (2006). 'Global public economics: Public goods and externalities,' Public Economics 18, 57-75.

Sheldon, I. (2006). 'Trade and environmental policy: A race to the bottom?,' Journal of Agricultural Economics 57, 365-392.

Stiglitz, J. (2006). 'A new agenda for global warming,' The Economist's Voice 3(7). Berkeley Electronic Press.

Turunen-Red, A. H., and A. D. Woodland. (2004). 'Multilateral reforms of trade and environmental policy,' Review of International Economics 12, 321-336.

Woodland, A. (1982). International trade and resource allocation, New York: North-Holland. 